\title{
Dairy Product Consumption in French Children in 2010
}

\author{
V. Coxam¹, C. Marmonier2*, E. Chazelle ${ }^{2}$, B. Coudray ${ }^{3}$ \\ ${ }^{1}$ Institut National de la Recherche Agronomique, Unité Mixte de Recherche 1019, Unitéde Nutrition Humaine, \\ Centre de Recherche en Nutrition Humaine Auvergne, Clermont-Ferrand, France \\ ${ }^{2}$ Direction des Affaires Scientifiques/Service Recherche Nutrition-Santé, Centre National Interprofessionnel de \\ I'Economie Laitière, Paris, France \\ ${ }^{3}$ Centre de Recherche et d'Information Nutritionnelles, Paris, France \\ Email: ${ }^{*}$ cmarmonier@cniel.com
}

Received 24 February 2015; accepted 14 April 2015; published 16 April 2015

Copyright () 2015 by authors and Scientific Research Publishing Inc.

This work is licensed under the Creative Commons Attribution International License (CC BY).

http://creativecommons.org/licenses/by/4.0/

(c) (i) Open Access

\begin{abstract}
Dairy food consumption is important for children as it contributes to the intake of key nutrients, especially calcium. The aim of the present paper is to provide an overview of dairy products consumption for French children, according to age, sex and type of dairy products. Adequacy of dairy and calcium intakes in line with French national guidelines " 3 portions of dairy products per day" were also evaluated. Data were extracted and analyzed from the CCAF-Comportementet Consommations Alimentairesen France-study. Seven-day questionnaires were administered to freeliving individuals from autumn 2009 to summer 2010. Subjects were children $(n=1171)$ aged 3 17 years. Dairy products contributed substantially to the intake of calcium, phosphorus, potassium, zinc, vitamin B2 and vitamin B12. A general decrease in DP consumption has been observed since 2003. This is most notably due to a lower milk intake which is not compensated by increased cheese or fresh dairy products. Most of children (67\%), and up to 73\% of adolescents (15 - 17 y), did not reach the recommended " 3 servings of dairy products per day". Twenty percent of children from the age of 6 and nearly $2 / 3$ of female adolescents did not reach their estimated average requirement for calcium. The overview of French dairy food consumption during childhood, of particular Public Health concern, emphasizes the need to encourage dairy consumption and particularly milk consumption at breakfast in order to maintain a nutrient adequacy in children and adolescents.
\end{abstract}

\section{Keywords}

Dairy Products, Calcium Intake, Children, Public Health

\footnotetext{
${ }^{*}$ Corresponding author.
} 


\section{Introduction}

Intake of high-calcium content foods is considered to be the most important lifestyle factor (in addition to exercise) for bone growth and development, as well as for the prevention of osteoporosis [1]-[3]. Adequate calcium intake throughout childhood and adolescence is needed to achieve maximum peak bone mass in young adulthood, which is a major determinant of bone health [4]-[8]. Dairy products represent a valuable dietary source of calcium due to the high content and high absorptive rate [9] [10]. In addition, milk and other dairy foods are important sources of macronutrients and micronutrients in the diets of children and adolescents [11], including protein, phosphorus and vitamin $\mathrm{D}$ which also contribute to bone health.

In France, the National Nutrition and Health Program ("Programme National Nutrition Santé" or PNNS) set up in 2001 aims to improve the health of the French population and reduce risk factors for chronic diseases through a focus on nutrition [11]. "Increase the calcium intake: reduce by $25 \%$ the population whose calcium intake falls below the recommended nutritional level" is still currently one of the nine high-priority nutritional objectives. In addition, "Improve calcium status in children and adolescents" is one of the ten specific nutritional objectives defined for specific population groups. Those targets are transposed into food-based dietary guidelines for the general population. Three to four portions of dairy products every day, as part of a healthy diet, are recommended in order to reach the average calcium requirements for children [11].

Although the issue of adequate calcium intake during childhood is a public health priority, only few data dealing with dairy product consumption and calcium levels in line with national recommendations are available [12]. In 1999, a French survey on individual behavior and food consumption was carried out in a representative sample of the general population by the CREDOC (Centre de Recherche pour l'Etudeetl'Observation des Conditions de Vie). Such a survey targeting behavior and food consumption (Comportementset Consommations Alimentairesen France, CCAF study), conducted every three years since 1999 allows the establishment of an accurate monitoring of food groups consumption.

The present study was carried out to address the specific issue of dairy products intake in French children and adolescents from the CCAF 2010 survey, focusing on amounts, types and time of consumption. Dairy and calcium intakes in line with the French dietary guidelines " 3 or 4 portions of DP per day" and average calcium requirement were also evaluated.

\section{Subjects and Methods}

\subsection{Study Design}

The results were extracted and analyzed from the national intake survey "Comportementset Consommations Alimentairesen France" (CCAF study) conducted by the CREDOC (Centre de Recherche pour l'Etude et l'Observation des Conditions de Vie), a non-profit governmental research organization whose goal is to track living conditions and which deals with food/beverage choices and intakes in France. The CCAF study was conducted in quota samples of the French population, both in children and adults. The details of participant recruitment and methods have been previously described [13]. A sample representative of the French population, accounting for 1171 children and adolescents aged 3 - 17 years, was used.

Seven-day questionnaires were administered to free-living individuals between autumn 2009 and summer 2010, to record fluid and solid food intakes. Data were obtained either from the parents or from the children themselves. Food and portion reporting was made easier by the use of a photographic reference book showing various portions of the common food and beverage choices [14]. Food intake was converted to nutrients using data recorded, crossed with the 2008 version of the French nutritional food composition database created by the CIQUAL (Informatics Centre for Food Quality) [15] [16].

\subsection{Measured Parameters}

From a nutritional point of view, dairy products category includes milk and products derived from milk mainly yogurt, soft white cheese, dairy desserts and soft or hard cheeses- and excludes butter and cream, due to their different nutritional composition, which belong to the fats and oils category. Three categories of DP were considered: milk, fresh DP (defined as yogurts and fermented milk products, soft white cheese and dairy desserts [desserts containing more than $50 \%$ of milk in the recipe]) and cheese. The occasion of DP consumption was also investigated in the observed age range (3 - 17 years). 
As an inherent part of the CCAF study, nutrient intakes and more particularly contribution of DP to total intake of micronutrients such as calcium, iodine, phosphorus, potassium, magnesium, selenium and vitamins B2, B12 and D, were studied with a specific focus on calcium. The rationale was supported by 1) nutritional contribution of DP to these micronutrient intakes and 2) high priority in terms of public health. Cheese and milk consumed as ingredients (e.g. incorporated in ready-cooked meals, pizzas or sandwiches) were not taken into account in the evaluation of the nutrient contributions.

Finally, adequacy with the French dietary guidelines for DP, which is 3 - $4 \mathrm{DP} / \mathrm{d}$, was investigated. The proportion of children meeting ( $\geq 3$ DP per day, [2.5; 4.5 portions]) or not meeting the recommendations ( $<3$ DP per day, [0; 2.5 portions]) was evaluated, a portion being specified as $150 \mathrm{ml}$ of milk, $30 \mathrm{~g}$ of cheese, $100 \mathrm{~g}$ of soft white cheese, $120 \mathrm{~g}$ of petit-suisse, $125 \mathrm{~g}$ of yogurt or fermented milk (according to the French National Nutrition and Health Survey ENNS 2006). Cheese and milk consumed as ingredients were taken into account in the evaluation of the portions. Moreover, the proportion of children with adequate dietary intake in each group was evaluated by estimating the percentage of those whose daily intake was above or equal to the Estimated Average Requirement (EAR, equivalent to 0.77 of the RDA). For example, EAR for calcium is $540 \mathrm{mg} / \mathrm{day}$ (RDA: 700 $\mathrm{mg}$ /day) for children aged 4 to 6, $700 \mathrm{mg}$ /day (RDA: $900 \mathrm{mg} /$ day) for children aged 7 to 9 and $925 \mathrm{mg} /$ day (RDA: $1200 \mathrm{mg} / \mathrm{day})$ from 10 to 19 years old [17].

\subsection{Statistical Analysis}

The statistical procedures used in this study were the same as those previously used in the context of the CCAF study [13]. Statistical analysis was performed with the SAS 9.2 software (SAS Institute Inc., Cary, NC, USA).

The generalized ranking procedure was used to improve the quality of estimators for each sample. The statistical procedures included PROC FREQ to assess the effects of independent variables on qualitative effects. To investigate the effects on quantitative variables (such as intakes), the generalized linear model (PROC GLM) and Student's t-tests were used. Differences were considered significant at $\mathrm{P}<0.05$. The prevalence of the adequacy of intake compared with requirements was estimated by the proportion of individuals in which intake was below the Estimated Average Requirement (EAR). Nutrient adequacy (above or equal to EAR versus below EAR) was tested using a Chi2 test of independence.

\section{Results}

\subsection{DP Consumption among French Children and Adolescents (Figure 1, Table 1 and Table 2)}

The average daily DP consumption in the studied population was: $316.5 \mathrm{~g}$. Girls consumed less DP than boys (P $<0.001)$. This pattern was true for both milk $(181.1 \mathrm{~g}$ in girls vs. $208.8 \mathrm{~g}$ in boys; $\mathrm{P}<0.01)$ and fresh dairy products (99.6 $\mathrm{g}$ in girls vs. $107.8 \mathrm{~g}$ in boys; $\mathrm{P}=0.05$ ), while cheese consumption was the same in both genders.

Moreover, the overall analysis of the CCAF surveys carried out between 2003 and 2010 indicates a decline in dairy products consumption, more evident from 2003 to 2007; milk being primarily concerned with this change (data not shown).

\subsection{Impact of Age}

A decline in total dairy products was observed with age for both genders (Figure 1, Table 1 and Table 2). This was mainly due to a marked drop in milk consumption in both girls (from $223.3 \mathrm{~g}$ in the $3-5 \mathrm{y}$ girls to $124.6 \mathrm{~g}$ in the $15-17 \mathrm{y}$ girls, Table 2, $\mathrm{P}<0.01$ ) and boys (from $251.2 \mathrm{~g}$ at the age of $3-5 \mathrm{y}$ to $184.6 \mathrm{~g}$ in the $15-17 \mathrm{y}$ boys, Table 2, $\mathrm{P}<0.01$ ). This pattern of milk consumption was not compensated by an increased intake of other types of DP (Figure 1). Mean daily cheese consumption did not significantly vary with age or gender (Table 1 and Table 2). Intake of fresh DP did not vary according to gender, but significantly decreased with age until 12 $14 \mathrm{y}$, particularly in girls (from $116.9 \mathrm{~g} /$ day in the $3-5 \mathrm{y}$ girls to $75.9 \mathrm{~g}$ in the $12-14 \mathrm{y}$ girls, $\mathrm{P}<0.05$, Table 2) and to a lesser extent in boys $(\mathrm{P}=0.08$, Table 1$)$.

\subsection{Time of Consumption}

Milk intake mainly occurred at breakfast (83\%) and afternoon snack (13\%), while fresh DP and cheese were consumed during main meals ( $42 \%$ and $45 \%$ at lunch and $40 \%$ and $50 \%$ at dinner, respectively). 


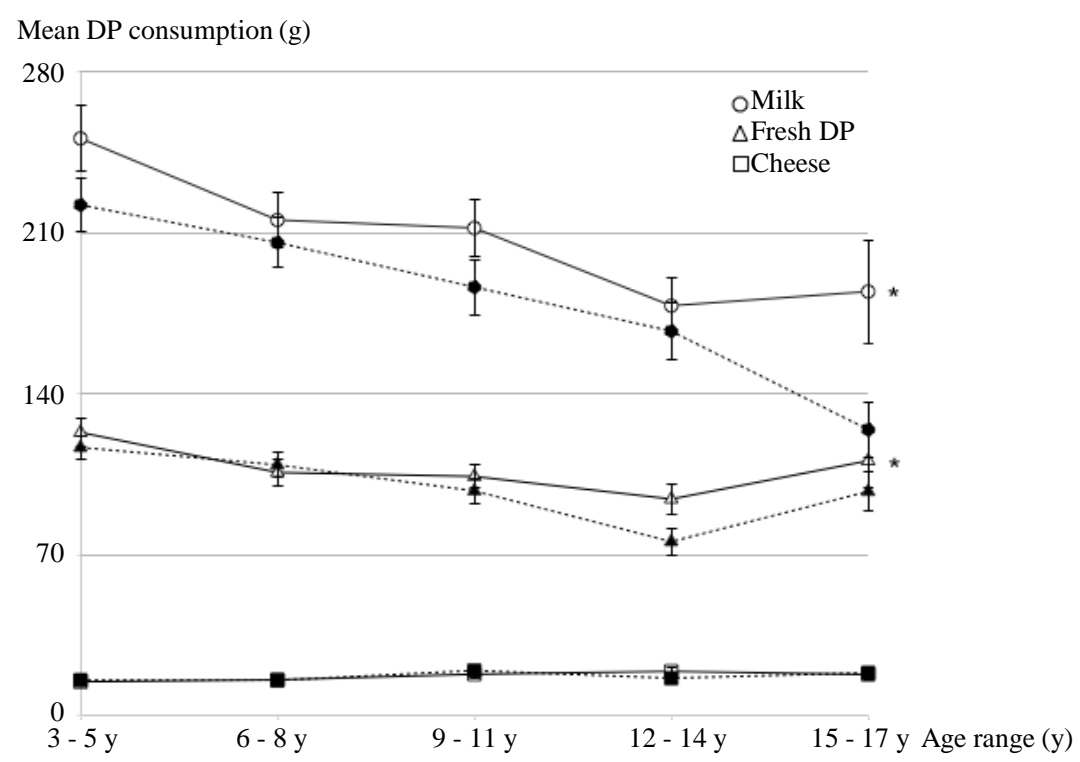

Figure 1. Daily intake of total types of dairy products in French boys and girls in 2010. — Boys ---- Girls. *Difference between boys and girls, $\mathrm{P}<0.05$.

Table 1. Daily intake of sub-types of dairy products (g) in five age groups of French boys.

\begin{tabular}{|c|c|c|c|c|c|c|c|c|c|c|c|}
\hline & \multicolumn{2}{|c|}{$\begin{array}{l}\text { Boys } 3-5 \text { y } \\
\text { (n 120) }\end{array}$} & \multicolumn{2}{|c|}{$\begin{array}{l}\text { Boys } 6-8 \text { y } \\
\text { (n 121) }\end{array}$} & \multicolumn{2}{|c|}{$\begin{array}{c}\text { Boys } 9-11 \text { y } \\
\text { (n 123) }\end{array}$} & \multicolumn{2}{|c|}{$\begin{array}{l}\text { Boys } 12-14 \text { y } \\
\text { (n 113) }\end{array}$} & \multicolumn{2}{|c|}{$\begin{array}{c}\text { Boys } 15-17 \text { y } \\
\text { (n 123) }\end{array}$} & \multirow{2}{*}{$\begin{array}{c}\text { P value } \\
\text { Age }\end{array}$} \\
\hline & Mean & SEM & Mean & SEM & Mean & SEM & Mean & SEM & Mean & SEM & \\
\hline $\begin{array}{l}\text { Fresh dairy } \\
\text { products }^{\mathrm{a}}\end{array}$ & 123.4 & 6.4 & 106 & 6.5 & 104.2 & 5.4 & 94.4 & 6.7 & 111.1 & 12.3 & $P=0.08$ \\
\hline $\begin{array}{l}\text { Yogurt, fermented } \\
\text { milk }\end{array}$ & 75.5 & 5.2 & 72.1 & 5.6 & 68.5 & 5 & 53.7 & 5.4 & 65.1 & 9.2 & - \\
\hline $\begin{array}{l}\text { Soft white cheese, } \\
\text { petit-suisses }\end{array}$ & 17.9 & 2.3 & 10.9 & 2.3 & 9 & 1.4 & 9.1 & 2.3 & 7.5 & 2.8 & - \\
\hline Dairy desserts & 29.9 & 4.2 & 23 & 2.5 & 26.8 & 2.8 & 3.6 & 3.5 & 38.4 & 8 & - \\
\hline Cheese $^{\mathrm{b}}$ & 14.9 & 1.4 & 15.8 & 1.5 & 18.2 & 1.7 & 19.5 & 1.9 & 18.1 & 2.7 & NS \\
\hline Milk & 251.2 & 14.9 & 215.7 & 12.7 & 212.3 & 13 & 178.5 & 12.9 & 184.6 & 22.6 & $\mathrm{P}<0.001$ \\
\hline
\end{tabular}

Values are expressed as means and SEM. ${ }^{a}$ Fresh dairy products: yogurt and fermented milk, soft white cheese, petit-suisse, and dairy desserts. ${ }^{\mathrm{b}}$ Cheese: processed, blue, goat, soft and pressed cheeses.

Table 2. Daily intake of sub-types of dairy products (g) in five age groups of French girls.

\begin{tabular}{|c|c|c|c|c|c|c|c|c|c|c|c|}
\hline & \multicolumn{2}{|c|}{$\begin{array}{l}\text { Girls } 3-5 \text { y } \\
\text { (n 115) }\end{array}$} & \multicolumn{2}{|c|}{$\begin{array}{l}\text { Girls } 6-8 \text { y } \\
\text { (n 115) }\end{array}$} & \multicolumn{2}{|c|}{$\begin{array}{l}\text { Girls } 9-11 \text { y } \\
\quad \text { (n 112) }\end{array}$} & \multicolumn{2}{|c|}{$\begin{array}{l}\text { Girls } 12-14 \text { y } \\
\text { (n 112) }\end{array}$} & \multicolumn{2}{|c|}{$\begin{array}{l}\text { Girls } 15-17 \text { y } \\
\text { (n 117) }\end{array}$} & \multirow{2}{*}{$\begin{array}{c}\text { P value } \\
\text { Age }\end{array}$} \\
\hline & Mean & SEM & Mean & SEM & Mean & SEM & Mean & SEM & Mean & SEM & \\
\hline $\begin{array}{l}\text { Fresh dairy } \\
\text { products }^{\mathrm{a}}\end{array}$ & 116.9 & 5.4 & 109.3 & 5.7 & 98 & 5.6 & 75.9 & 6 & 97.7 & 8.8 & $\mathrm{P}<0.001$ \\
\hline $\begin{array}{l}\text { Yogurt, fermented } \\
\text { milk }\end{array}$ & 70.8 & 4.8 & 69.1 & 5.2 & 61.5 & 5 & 44.7 & 4.4 & 65.1 & 7.8 & - \\
\hline $\begin{array}{l}\text { Soft white cheese, } \\
\text { petit-suisses }\end{array}$ & 19.6 & 2.4 & 14.2 & 2.1 & 11.7 & 2 & 6.4 & 1.3 & 9.9 & 3 & - \\
\hline Dairy desserts & 26.4 & 2.8 & 26 & 3 & 24.7 & 3.2 & 24.8 & 3.1 & 22.7 & 3.6 & - \\
\hline Cheese $^{\mathrm{b}}$ & 15.7 & 1.4 & 15.6 & 1.4 & 19.8 & 2 & 16.5 & 1.6 & 18.9 & 2.3 & NS \\
\hline Milk & 222.3 & 12.1 & 205.9 & 11.2 & 186.6 & 12.4 & 167.4 & 12.8 & 124.6 & 12.5 & $\mathrm{P}<0.001$ \\
\hline
\end{tabular}

Values are expressed as means and SEM. ${ }^{\mathrm{a}}$ Fresh dairy products: yogurt and fermented milk, soft white cheese, petit-suisse, and dairy desserts. ${ }^{\mathrm{b}}$ Cheese: processed, blue, goat, soft and pressed cheeses. 
At breakfast, milk was increasingly replaced by other drinks: $72 \%$ of the breakfast beverages were mainly milk in the 3 - 11 y children, against 57\% to that of age 12 - $17 \mathrm{y}$. The other main beverages ingested at breakfast were fruit juices (22\% and 29\%) and hot beverages (2\% and $8 \%$ ) in the 3 - 11 y and 12 - 17 y children, respectively.

\subsection{Contribution of DP to Calcium Intake and Calcium Status in French Children (Age 3 - 17 Years)}

In the overall studied population (age 3 - $17 \mathrm{y}$ ), DP substantially (first source) contributed to calcium intake (51\%). The mean daily calcium consumption was $835.2 \mathrm{mg}$ at the age of 3 - 5 y (i.e. $59 \%$ of Ca intake), 863.8 mg between 6 - $11 \mathrm{y} \mathrm{(53 \% )} \mathrm{and} 900.6 \mathrm{mg}$ in the 12 - 17 y group (45\%), respectively. The second source of calcium, albeit far lesser, was from sweets and pastries in both the 3 - 5 y (10\% of Ca intake) and 6 - 11 years aged children (12\%). In adolescents (12 - $17 \mathrm{y})$, ready-cooked meals were the second source of calcium (15\%).

Regarding the overall calcium status, 1/3 of children showed inadequate calcium intake (Figure 2). The percentage of individuals below the EAR differed according to sex $(\mathrm{P}<0.001)$ and age $(\mathrm{P}<0.001)$. The proportion of children not meeting the EAR was higher in girls (42\%) than in boys (32\%), and higher in adolescents than in younger children. Almost 70\% of French adolescent girls (12 - 14 y) had a daily intake of calcium below the EAR.

More than 2/3 of the children did not achieve the " 3 - 4 portions of dairy products per day" (Figure 3). As early as 3 to $5 \mathrm{y}, 53 \%$ of boys and $61 \%$ of girls did not follow the national dietary guidelines. Three-fourths of 9 y old adolescent girls did not reach the objective. Sixty-nine percent of boys and up to 77\% of girls aged 15 - 17 $\mathrm{y}$ ate less than 3 portions daily. Thus, a higher proportion of those individuals consuming less than three DP a day was observed in girls ( $64 \%$ of boys and $71 \%$ of girls, $\mathrm{P}<0.05$ ).

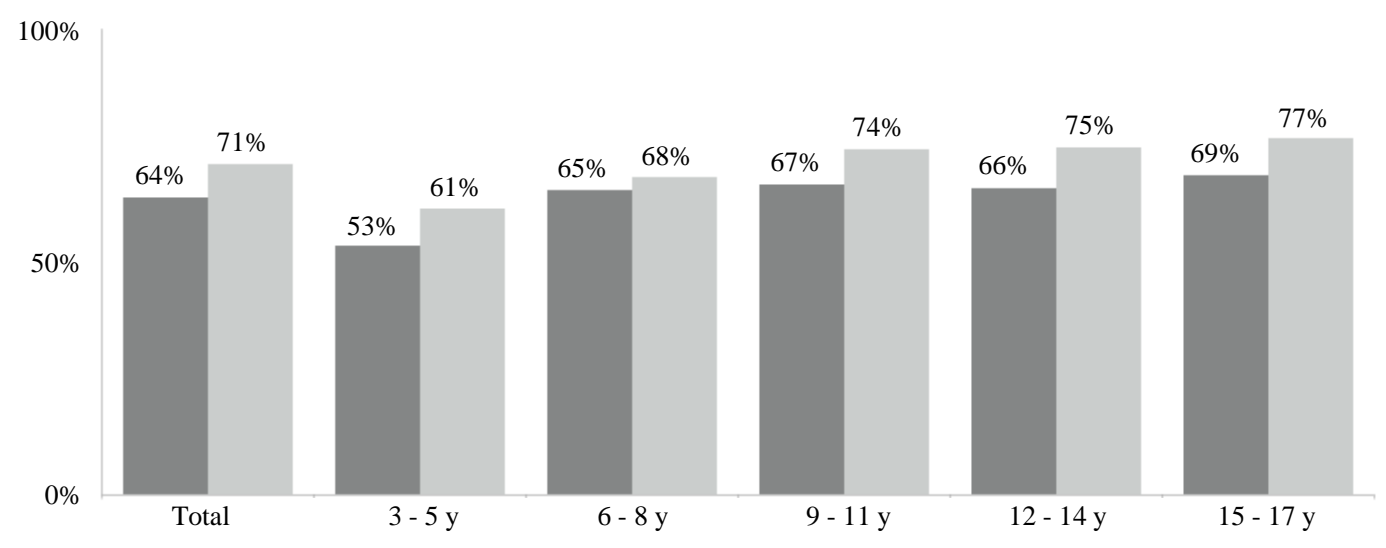

Figure 2. Percentage of children and adolescents whose daily calcium intake were below the EAR ( $<$ EAR).

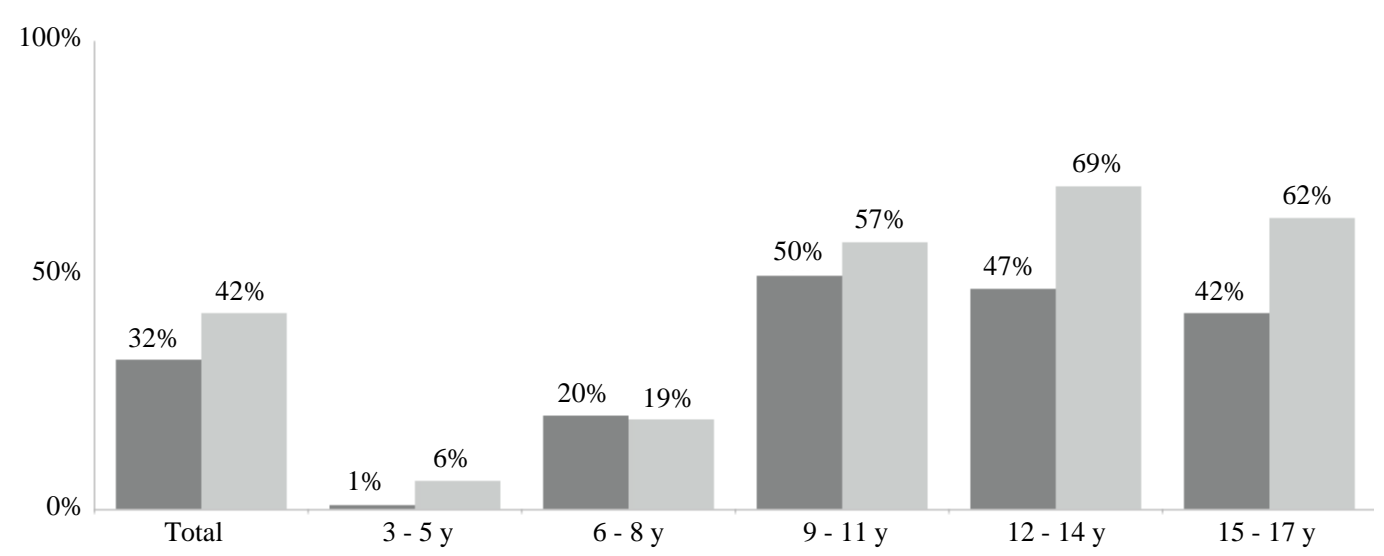

Figure 3. Percentage of children and adolescents not meeting the national recommendation "3 portions of dairy products per day" $(<3)$. 


\subsection{Contribution of DP to Micronutrients Status in French Children (Age 3 - 17 Years)}

DP contributed substantially (as the first source) to the intake of iodine (39\%), phosphorus (28\%), potassium $(20 \%)$ and, to a lesser extent, zinc $\left(26 \%, 2^{\text {nd }}\right.$ source), magnesium $\left(17 \%, 3^{\text {rd }}\right.$ source $)$ and selenium $\left(11 \%, 4^{\text {th }}\right.$ source). Nevertheless, in young children (3 - 5 years), DP were still the main source of magnesium (23\%) and zinc (34\%). Among DP, milk contributed the most to the intake of these nutrients (20\% for iodine; $14 \%$ of the phosphorus and $13 \%$ of the potassium). In fact, $83 \%, 65 \%$ and $57 \%$ of the children showed adequate intakes of selenium, magnesium and zinc, respectively, while a high proportion consumed less than the EAR for iodine (41\%; the average intake being even lower in girls and decreasing with age).

With regard to water-soluble vitamins, DP were also significant contributors of vitamin B2 (36\%) and vitamin B12 (25\%, second source), milk being the main of these micronutrients. A high percentage of those children studied had adequate vitamin B2 and vitamin B12 intakes as less than 7\% and 1\% of them consumed less than the EAR, respectively.

The overall vitamin D intake in this population was $1.86 \mu \mathrm{g} / \mathrm{d}$. Consequently, a huge percentage of children did not reach the EAR: $94 \%$ (ranging from $88 \%$ in 12 - 17 y boys to $98 \%$ in 6 - 8 y girls). Contribution of DP was estimated to reach $13 \%$, behind meat/seafood/eggs (45\%), ready-cooked meals (22\%) and sweets and pastries (14\%) groups. Among DP, fresh DP were the main contributors (6\%).

Finally, DP were the second source of proteins (21\%) after the meat/seafood/eggs group (33\%).

\section{Discussion}

The present study is the first survey targeting DP consumption in French children and adolescents taking into account amounts, types of products, time of consumption, and adequacy of calcium intake with regard to French dietary guidelines and Estimated Average Requirement. The data were collected from a large dietary survey (2010 CCAF-CREDOC study) carried out between autumn 2009 and summer 2010, among a national and representative sample of 1171 children aged between 3 to 17 years.

The results provide important insights into the current state of eating habits among children and adolescents in the French population. It clearly highlights a general decrease in DP consumption since 2003, most notably due to a lower milk intake and not compensated by increased cheese or fresh DP intake. In fact, there is evidence that milk consumption has fallen over the past 20 - 25 years in many countries [12] [18]. Moreover, mean consumption of DP decreased with age, the decline in milk consumption starting from adolescence. Similarly, in Australian adolescents, mean dairy intake has been reported to move from 536 g/day to 464 g/day (P<0.01), mostly due to a decrease in regular milk, although flavored milk consumption increased in boys [19]. In the present study, such a change can be presently explained by a higher number of milk non-consumers according to age (a 3-fold increase between younger and older, 30\% of 15 - 17 y adolescents being non-consumers of milk), but also due to a decline in breakfast consumption, a key time for milk intake in children. Indeed Hébel et al. recently showed hat from 2003 to 2007, the proportion of adolescents aged 13 - 19 y eating 7 breakfasts per week fell from $79 \%$ to 54\%, before rising slightly to 59\% in 2010 [20]. As a matter of fact, decreased breakfast consumption in children and adolescents could lead to an overall decrease of foods normally consumed at this time, such as milk. Among those who continue to eat breakfast, it seems that milk has been increasingly replaced by other drinks such as fruit juices and hot beverages. According to 2010 HSBC survey college students who report eating breakfast daily have better eating habits regardless of their gender [21].

The overall adequacy of DP consumption for the coverage of recommended intakes (" 3 - 4 portions of dairy foods per day, as part of a balanced diet”) was also investigated. Actually, 2/3 of children consumed fewer than 3 DP per day. Such results are in line with the data from the HELENA study conducted in 3000 European adolescents, showing that adolescents consumed less than two-thirds of the recommended amount of DP [22]. Our results are also in, accordance with the French ENNS study performed in 2006 [23]. In the present survey, foods that contributed the most to dietary intake of calcium were DP (51\%), including milk (26\%). Consistently with data, INCA2 survey conducted in 2006-2007 showed that DP and milk provided 53\% and 25\% (respectively) of the calcium consumed by French children [24]. Basically, DP have long been recognized as an excellent source of calcium due to their high mineral content and bioavailability as well as providing a high density of other synergistic nutrients [8] [25] [26]. Therefore, failure to follow guidelines for DP has a strong impact on covering the calcium requirement [27]-[30]. According to present results, the mean daily calcium intake remained stable with age (from 835 at 3 - 5 y to $901 \mathrm{mg}$ per day at 12 - 17 y), although EAR increased from 540 mg (4 - 6 y) to 925 
mg per day (10 - 19 y). As a consequence 1/5 of children aged 6 - 8 y had a calcium intake below that of the EAR established for their age. This percentage increased with age was dramatically more noticeable in girls (up to $70 \%$ of the French adolescent girls have a daily intake of calcium below the EAR). Moreover, in a representative sample of the Spanish schoolchildren population, dairy products were the main calcium source (65\%) and calcium intake was $860 \mathrm{mg}$ per day (79\% of the recommendations). Seventy-seven percent of the children had calcium intakes lower than recommended and $40 \%$ below of $67 \%$ of recommended intakes [31]. Albeit possible, the consumption of alternative sources of calcium-due to lower diversity, accessibility and convenience than dairy - makes the challenge of meeting the recommended intake harder. Indeed most individuals who avoid milk fail to adjust their diets in order to replace the nutrients found in milk [32]. Furthermore, daily milk could be displaced by soft drinks containing caffeine and phosphoric acids which may have additional and direct deleterious effects on health [2].

There is a consensus on the role of calcium for normal growth and development and general bone health [2] [4]-[7]. Consequently, because dairy products represent the most valuable dietary source of calcium due to the high content, high absorptive rate and because they also contain other key nutrients including protein, phosphorus and secondarily vitamin D (in whole milk and fortified milk), they have been positively linked to bone health in various observational retrospective and intervention studies [2].

Beyond calcium, DP group was the first source of iodine, phosphorus, potassium, and vitamin B2 in children aged 3 - 17 years, and also contributes substantially to the intake of zinc, magnesium, selenium and vitamin B12. Thus adequate consumption of dairy products in line with food-based dietary guidelines could not only help meet nutritional requirements for calcium but also significantly improve the intake of minerals and trace elements, in particular for iodine, iodine deficiency being one of the objectives defined in the PNNS. This is consistent with previous studies conducted in other parts of Europe [12]-[29]. In the same way, according to the US NHANES survey [18], milk was the primary contributor of calcium $(52 \%-62 \%)$, phosphorus (37\% - 42\%), magnesium (27\% - 28\%), and potassium (32\% - 37\%). Similar data have been reported in Australia as well [30].

The data dealing with DP intake in French children are consistent with those from the INCA2 survey [24]. Nevertheless, methodologies used to investigate dietary intakes are, to some extent, imperfect, each having their own limitations. Incomplete reporting can occur for example due to subjects not remembering having consumed specific foods or beverages, inaccurately measuring or estimating portion sizes, or purposely failing to record specific items. Providing easy-to-use booklets with guidelines for appropriate methods for weighing and measuring foods and beverages, training subjects how to record, and providing resources for measuring can all help to increase accuracy. With this in mind, the intake data presented in this study were self-reported, either from the parents or from the children themselves, using seven-day questionnaires. Portion reporting was made easier by the use of a validated photographic book showing various portions of common food and beverage choices [14].

\section{Conclusions}

This study shows that a high proportion of French children do not meet the national dietary guidelines for DP. This situation is particularly worrying at the ages when calcium intake is important for peak bone mass acquisition, especially for girls, a population with a high risk of osteoporosis in later life. Moreover, the food choices in childhood have a high probability of being carried through into adult life. Faced with this public health challenge, further efforts through educational initiatives are thus needed to promote DP consumption in French children and adolescents. A huge advantage of DP is their relatively low cost with regard to nutritional density, despite their low energy contribution [33] [34]. Encouraging milk intake at breakfast and consumption of other DP (fresh DP and cheese) at other mealtimes should continue to be a major focus of action in order to reach the recommended calcium intake, meet many nutrient requirements and improve overall diet quality.

- There is a general decrease in DP consumption since 2003, most notably due to a lower milk intake.

- Dairy and particularly milk are key contributors to ensure nutrient adequacy in children and adolescents.

- A high proportion of French children do not meet the national dietary guidelines for dairy products (3 - 4 DP/day).

\section{Acknowledgements}

All authors contributed to interpretation of the data of the submitted manuscript. The extraction and analysis of data about dairy product intakes collected in the context of the CCAF study were carried out by the CREDOC. 
The authors are grateful to Gabriel Tavoularis (CREDOC) for his help in the interpretation of the statistical analysis.

\section{Conflict of Interest}

This study was supported by the CNIEL (Centre National Interprofessionnel de l'EconomieLaitière). CM and EC were employees of the CNIEL. BC was an employee of the Centre de Recherché et d'Information Nutritionnelles, the Health Department of the CNIEL. The Human Nutrition Unit UMR1019 (Unité de Nutrition Humaine Unité Mixte de Recherche 1019) received some financial support from the CNIEL for contributing to the work performed.

\section{References}

[1] Heaney, R.P. (2013) Dairy Intake, Dietary Adequacy, and Lactose Intolerance. Advances in Nutrition, 4, 151-156. http://dx.doi.org/10.3945/an.112.003368

[2] Rizzoli, R., Bianchi, M.L., Garabedian, M., McKay, H.A. and Moreno, L.A. (2010) Maximizing Bone Mineral Mass Gain during Growth for the Prevention of Fractures in the Adolescents and the Elderly. Bone, 46, 294-305. http://dx.doi.org/10.1016/j.bone.2009.10.005

[3] Huncharek, M., Muscat, J. and Kupelnick, B. (2008) Impact of Dairy Products and Dietary Calcium on Bone-Mineral Content in Children: Results of a Meta-Analysis. Bone, 43, 312-321. http://dx.doi.org/10.1016/j.bone.2008.02.022

[4] Wosje, K.S. and Specker, B.L. (2000) Role of Calcium in Bone Health during Childhood. Nutrition Reviews, 58, 253-268. http://dx.doi.org/10.1111/j.1753-4887.2000.tb01879.x

[5] Cashman, K.D. (2002) Calcium Intake, Calcium Bioavailability and Bone Health. British Journal of Nutrition, 87, S169-S177. http://dx.doi.org/10.1079/BJNBJN/2002534

[6] Prentice, A., Schoenmakers, I., Laskey, M.A., de Bono, S., Ginty, F. and Goldberg, G.R. (2006) Nutrition and Bonegrowth and Development. Proceedings of the Nutrition Society, 65, 348-360. http://dx.doi.org/10.1079/PNS2006519

[7] Boot, A.M., de Ridder, M.A., van der Sluis, I.M., van Slobbe, I., Krenning, E.P. and Keizer-Schrama, S.M. (2010) Peak Bone Mineral Density, Lean Body Mass and Fractures. Bone, 46, 336-341. http://dx.doi.org/10.1016/j.bone.2009.10.003

[8] Caroli, A., Poli, A., Ricotta, D., Banfi, G. and Cocchi, D. (2011) Invited Review: Dairy Intake and Bone Health: A Viewpoint from the State of the Art. Journal of Dairy Science 94, 5249-5262. http://dx.doi.org/10.3168/jds.2011-4578

[9] Guéguen, L. and Pointillart, A. (2000) The Bioavailability of Dietary Calcium. Journal of the American College of Nutrition, 19, 119S-136S. http://dx.doi.org/10.1080/07315724.2000.10718083

[10] Rizzoli, R., Abraham, C. and Brandi, M.L. (2014) Nutrition and Bone Health: Turning Knowledge and Beliefs into Healthy Behaviour. Current Medical Research Opinion, 30, 131-141. http://dx.doi.org/10.1185/03007995.2013.847410

[11] Hercberg, S., Chat-Yung, S. and Chauliac, M. (2008) The French National Nutrition and Health Program: 2001-20062010. International Journal of Public Health, 53, 68-77. http://dx.doi.org/10.1007/s00038-008-7016-2

[12] Dror, D.K. and Allen, L.H. (2014) Dairy Product Intake in Children and Adolescents in Developed Countries: Trends, Nutritional Contribution, and a Review of Association with Health Outcomes. Nutrition Reviews, 72, 68-81. http://dx.doi.org/10.1111/nure.12078

[13] Hébel, P. (2007) Comportements et Consommations Alimentaires en France. Lavoisier Tec and Doc, Paris.

[14] Hercberg, S., Deheeger, M. and Preziosi, P., SU-VI-MAX (1994) Portions alimentaires. Manuel photos pour l'estimation des quantités (Portion Sizes: Picture Booklet for the Estimation of Quantities). Polytechnica, Paris.

[15] Favier, J.C., Ireland-Ripert, J., Toque, C. and Feinberg, M. (1995) Répertoire général des aliments-Table de composition (Régal French Food Composition Table). 2nd Edition, Lavoisier, Paris.

[16] Table de composition nutritionnelle des aliments Ciqual (French Food Composition Table Ciqual). http://www.afssa.fr/TableCIQUAL/

[17] Nutrition Committee of the French Society of Paediatrics (2001) Recommended Dietary Allowances for Infants, Children and Adolescents. In: Martin, A., Ed., Recommended Dietary Allowances for the French Population, 3rd Edition, Editions TEC et DOC, Paris, 255-291.

[18] Fulgoni, V.L. and Quann, E.E. (2012) National Trends in Beverage Consumption in Children from Birth to 5 Years: Analysis of NHANES across Three Decades. Nutrition Journal, 11, 92. http://dx.doi.org/10.1186/1475-2891-11-92

[19] Parker, C.E., Vivian, W.J., Oddy, W.H., Beilin, L.J., Mori, T.A. and O’Sullivan, T.A. (2012) Changes in Dairy Food 
and Nutrient Intakes in Australian Adolescents. Nutrients, 4, 1794-1811. http://dx.doi.org/10.3390/nu4121794

[20] Hébel, P. (2013) Le petit déjeuner en perte de vitesse. CREDOC Consommation et modes de vie No. 259.

[21] Inpes (2010) La santédes collégiens en France. Donnéesfrançaises de l'enquêteinternationale Health Behaviour in School-Aged Children (HBSC).

[22] Diethelm, K., Jankovic, N., Moreno, L.A., Huybrechts, I., De Henauw, S., De Vriendt, T., et al. (2012) Food Intake of European Adolescents in the Light of Different Food-Based Dietary Guidelines: Results of the HELENA (Healthy Lifestyle in Europe by Nutrition in Adolescence) Study. Public Health Nutrition, 15, 386-398. http://dx.doi.org/10.1017/S1368980011001935

[23] Unitéde surveillance et d’épidémiologie nutritionnelle (2007) Étude nationale nutrition santé(ENNS, 2006)—Situation nutritionnelle en France en 2006 selon les indicateurs d'objectif et les repères du Programme national nutrition santé(PNNS). Institut de veille sanitaire, Universitéde Paris 13, Conservatoire national des arts et métiers, 74 p.

[24] Coudray, B. (2011) The Contribution of Dairy Products to Micronutrient Intakes in France. Journal of the American College of Nutrition, 30, 410S-414S. http://dx.doi.org/10.1080/07315724.2011.10719984

[25] Kosikowski, F.V. and Mistry, V.V. (1997) Cheese and Fermented Milk Foods, Vol. 1, Origins and Principles. 3rd Edition.

[26] Gaucheron, F. (2011) Milk and Dairy Products: A Unique Micronutrient Combination. Journal of the American College of Nutrition, 30, 400S-409S. http://dx.doi.org/10.1080/07315724.2011.10719983

[27] Black, R.E., Williams, S.M., Jones, I.E. and Goulding, A. (2002) Children Who Avoid Drinking Milk Have Low Dietary Calcium Intakes and Poor Bone Health. American Journal of Clinical Nutrition, 76, 675-680.

[28] Weinberg, L.G., Berner, L.A. and Groves, J.E. (2004) Nutrient Contributions of Dairy Foods in the United States, Continuing Survey of Food Intakes by Individuals, 1994-1996, 1998. Journal of the American Dietetic Association, 104, 895-902. http://dx.doi.org/10.1016/j.jada.2004.03.017

[29] Vissers, P.A.J., Streppel, M.T., Feskens, E.J.M. and de Groot, L.C. (2011) The Contribution of Dairy Products to Micronutrient Intake in The Netherlands. Journal of the American College of Nutrition, 30, 415S-421S. http://dx.doi.org/10.1080/07315724.2011.10719985

[30] Fayet, F., Ridges, L.A., Wright, J.K. and Petocz, P. (2013) Australian Children Who Drink Milk (Plain or Flavored) Have Higher Milk and Micronutrient Intakes but Similar Body Mass Index to Those Who Do Not Drink Milk. Nutrition Research, 33, 95-102. http://dx.doi.org/10.1016/j.nutres.2012.12.005

[31] Ortega, R.M., López-Sobaler, A.M., Jiménez Ortega, A.I., NaviaLombán, B., Ruiz-RosoCalvo de Mora, B., Rodríguez-Rodríguez, E., et al. (2012) Food Sources and Average Intake of Calcium in a Representative Sample of Spanish Schoolchildren. Nutricion Hospitalaria, 27, 715-723.

[32] Barger-Lux, M.J., Heaney, R.P., Packard, P.T., Lappe, J.M. and Recker, R.R. (1992) Nutritional Correlations of Low Calcium Intake. Clin Appl Nutr, 2, 39-44.

[33] Drewnowski, A. (2011) The Contribution of Milk and Milk Products to Micronutrient Density and Affordability of the U.S. Diet. Journal of the American College of Nutrition, 30, 422S-428S.

[34] Primavesi, L., Caccavelli, G., Ciliberto, A. and Pauze, E. (2014) Nutrieconomic Model Can Facilitate Healthy and Low-Cost Food Choices. Public Health Nutrition, 18, 827-835. http://dx.doi.org/10.1017/S1368980014002651

\section{Abbreviations}

AFSSA: French Agency for Food Safety;

CCAF: Comportement et Consommations Alimentaires en France;

CREDOC: Centre de Recherche pour l'Etude et l'Observation des Conditions de Vie;

DP: Dairy Products;

EAR: Estimated Average Requirement;

INCA: Etude Individuelle Nationale des Consommations Alimentaires;

PNNS: Programme National Nutrition Santé;

RDA: Recommended Dietary Allowance. 